\title{
Myosin VIla Participates in Opsin Transport through The Photoreceptor Cilium
}

\author{
Xinran Liu, ${ }^{1}$ Igor P. Udovichenko,, ${ }^{1}$ Stephen D.M. Brown, ${ }^{2}$ Karen P. Steel, ${ }^{3}$ and David S. Williams ${ }^{1}$ \\ ${ }^{1}$ Departments of Pharmacology and Neurosciences, University of California at San Diego School of Medicine, La Jolla, \\ California 92093-0983, 2Medical Research Council Mammalian Genetics Unit and Mouse Genome Centre, Harwell \\ OX11 ORD, United Kingdom, and ${ }^{3}$ Medical Research Council Institute of Hearing Research, University Park, Nottingham \\ NG7 2RD, United Kingdom
}

Two types of Usher syndrome, a blindness-deafness disorder, result from mutations in the myosin VIla gene. As for most other unconventional myosins, little is known about the function or functions of myosin VIla. Here, we studied the photoreceptor cells of mice with mutant myosin VIla by electron immunomicroscopy and microscopic autoradiography. We found evidence that myosin VIla functions in the connecting cilium of each photoreceptor cell and participates in the transport of opsin through this structure. These findings provide the first direct evidence that opsin travels along the connecting cilium en route to the outer segment. They demonstrate that a myosin may function in a cilium and suggest that abnormal opsin transport might contribute to blindness in Usher syndrome.

Key words: myosin; molecular motor; cilium; photoreceptor; opsin; Usher syndrome
Myosin VIIa is a large putative actin-based mechanoenzyme (Hasson et al., 1995; Chen et al., 1996; Weil et al., 1996). It is present in a variety of tissues (Hasson et al., 1995) where it is a common component of cilia and actin-rich microvilli (Wolfrum et al., 1998). However, its most critical roles appear to be in the retina and inner ear. Mutations in the myosin VIIa gene are the cause of the combined blindness and deafness found in Usher syndrome type 1B (Weil et al., 1995) and an atypical form of Usher syndrome (Liu et al., 1998b). Within the retina, myosin VIIa has been immunolocalized in the apical processes of the retinal pigment epithelium (RPE) (Hasson et al., 1995; ElAmraoui et al., 1996; Liu et al., 1997a), where it is required for correct positioning of melanosomes (Liu et al., 1998a). Recently, it has also been immunodetected in the connecting cilium of the photoreceptor cells (Liu et al., 1997a); i.e., the physical link between the inner and outer segments of each cell (Fig. 1a).

The renewal of the phototransductive disk membranes in the outer segments is a major cellular process in the retina. From published data on disk renewal rate (Guerin et al., 1993), opsin concentration in the disk membranes (Corless et al., 1976), and the number of photoreceptor cells in a retina (Curcio et al., 1990), it follows that each human eye synthesizes de novo some 10 billion opsin molecules per second. The opsin molecules and other phototransductive proteins are synthesized in the proximal region of the inner segment (Young, 1967). They are transported to

\footnotetext{
Received Feb. 22, 1999; revised May 10, 1999; accepted May 12, 1999.

This work was supported by National Institutes of Health Grant EY07042, the Foundation Fighting Blindness, the Medical Research Council, European Commission, and Defeating Deafness. We thank J. Yamada for assisting with measurements of number of cell nuclei, outer segment length, immunolabel density, and radioactive band migration; T. Self, J. Fleming, and R. Libby for help in preparing samples; L. Goldstein, members of his laboratory, B. Ondek, and R. Libby for helpful discussions and comments; R. Molday and P. Hargrave for gifts of opsin monoclonal antibodies; and G. Travis for the gift of the peripherin/rds antibody.

Correspondence should be addressed to David S. Williams, Department of Pharmacology, University of California at San Diego School of Medicine, Mail code 0983, 9500 Gilman Drive, La Jolla, CA 92093-0983.

Copyright (C) 1999 Society for Neuroscience 0270-6474/99/196267-08\$05.00/0
}

the distal inner segment (Papermaster et al., 1985), and, from there, they are transported to the outer segment. Little is known about these transport processes, even to the extent that it has been a long-standing mystery as to which route opsin takes as it travels from the inner to the outer segment (Besharse and Horst, 1990). The localization of myosin VIIa in the connecting cilium suggests that this putative molecular motor might be involved in transporting opsin and other phototransduction proteins through this structure on their way to the outer segment.

To explore this possibility, we examined the photoreceptor cells of shaker1 mice, which have known mutations in myosin VIIa (Gibson et al., 1995; Mburu et al., 1997). The phenotype of shaker1 photoreceptors corroborates the immunolocalization data that myosin VIIa does function in the connecting cilium. Furthermore, it indicates that myosin VIIa participates in the transport of opsin through this structure.

\section{MATERIALS AND METHODS}

Animals. Mice were bred from homozygous $\times$ heterozygous or heterozygous $\times$ heterozygous parents and maintained on a $12 \mathrm{hr}$ light/dark cycle, with exposure to 10-50 lux of fluorescent lighting during the light phase. They were treated according to National Institutes of Health and University of California at San Diego (UCSD) animal care guidelines and in full compliance with the British Home Office regulations. Ages of the mice ranged from 1 to 8 months. The $M y o 7 a^{\text {shl }}$ mice were purchased from The Jackson Laboratory (Bar Harbor, ME; stock number JR0271). Mutant $M y o 7 a^{s h 1}$ mice had the same chinchilla pigmentation as their controls. The Myo $7 a^{4494 S B}$ and Myo $7 a^{4626 S B}$ mice were obtained from ENU-induced mutations induced on a BALBc background. They were back-crossed repeatedly to the BS strain used at Oak Ridge. Most mutants from these Myo $7 a^{4494 S B}$ and Myo7a ${ }^{4626 S B}$ strains are albino, and most of the controls are pigmented (either agouti or chinchilla). However, in the present study, we matched the pigmentation between mutant and control whenever possible. Some of the Myo $7 a^{4494 S B}$ and Myo $7 a^{4626 S B}$ mice used for opsin measurements were crossed additionally to $\mathrm{CBA} / \mathrm{Ca}$ once and then intercrossed. Homozygous mutants of all alleles were evident by their hyperactivity, head-tossing, and circling behavior caused by vestibular dysfunction (Lord and Gates, 1929; Gibson et al., 1995). Littermate controls were either heterozygotes or wild-type. Myo7ashi mice were identified by DNA sequencing and/or hybridization tests, as 
Figure 1. Immunogold localization of myosin VIIa in the photoreceptor cell. $a$, Diagram of a rod photoreceptor. ROS, Outer segment (which is made up of a stack of opsin-containing disk membranes); $C C$, connecting cilium; $B B$, distal pair of basal bodies; $I S$, inner segment. The top bracket (left) indicates the $1 \mu \mathrm{m}$ length of connecting cilium, along which opsin immunogold label was quantified (see Materials and Methods). The bottom bracket (partially shown) indicates the $1 \mu \mathrm{m}$ length of inner segment plasma membrane, along which opsin immunogold label was quantified. $b$, Photoreceptor cells (two connecting cilia are shown) from a wild-type retina, immunogold-labeled with the myosin VIIa tail domain antibody. Scale bar, $0.5 \mu \mathrm{m}$. $c$, Electron micrograph of a photoreceptor cell from a homozygous mutant $M y o 7 a^{\text {sh } 1}$ retina, immunogold-labeled with the myosin VIIa tail domain antibody. Same magnification as in $b$. In both the mutant and control, label is predominantly in the periphery of the connecting cilium. Note that where a section passes obliquely through the periphery of a cilium (distally in the left one in $b$, proximally in the other two), label is more dense because of greater exposure of the periphery.
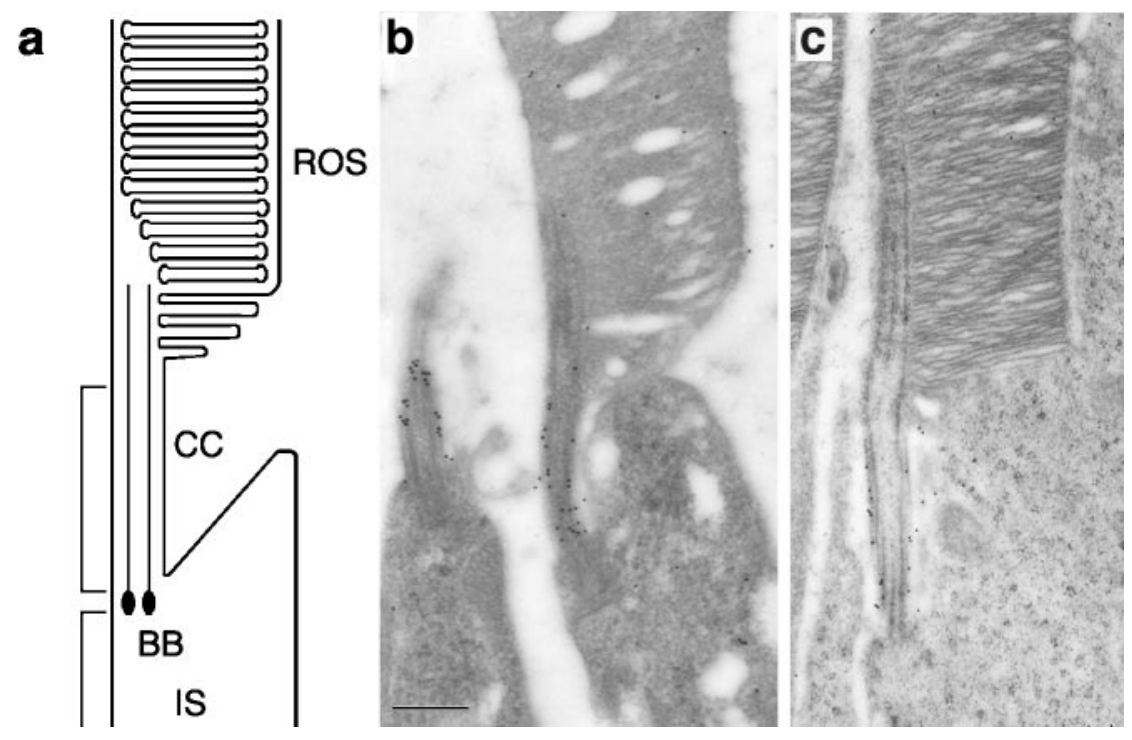

Figure 2. Immunogold localization of opsin in Myo $7 a^{s h 1}$ photoreceptor cells. $a$, Electron micrograph of a photoreceptor cell from a heterozygous mouse. The lack of label in the connecting cilium is typical of that found in wild-type animals (Nir et al., 1984; Besharse et al., 1985). Scale bar, $0.5 \mu \mathrm{m}$. $b$, Electron micrograph of a photoreceptor cell from a homozygous mutant $M y o 7 a^{\text {shl }}$ mouse. The connecting cilium is labeled in a manner that we have never observed in wild-type animals either in this study or in previous ones. The bracket indicates the $1 \mu \mathrm{m}$ length of connecting cilium, along which opsin immunogold label was counted (compare Fig. 1a). Same magnification as in $a$. The mice were 3-month-old littermates.
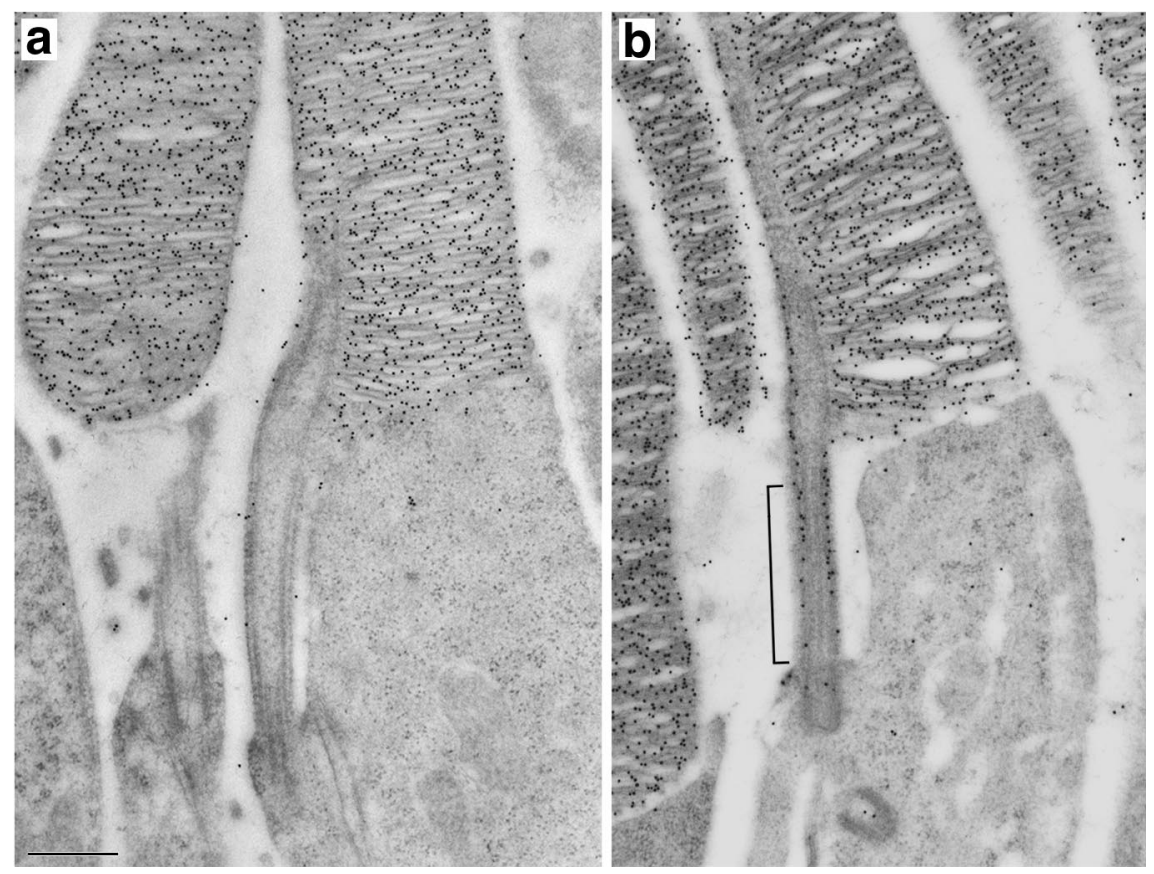

before (Liu et al., 1998a), but heterozygous Myo7a ${ }^{4494 S B}$ and Myo $7 a^{4626 S B}$ mice were not distinguished from wild-type littermates. All data and images presented in the present paper were obtained from light-adapted animals, which were killed between 2 and $6 \mathrm{hr}$ after the onset of the light phase of the light/dark cycle. Retinas from three dark-adapted Myo7a $a^{\text {sh } 1}$ mutants and three dark-adapted littermate controls, which were all killed under dim red light between 3 and $5 \mathrm{hr}$ after the onset of the dark phase, were also examined with respect to opsin distribution; qualitatively, they appeared no different from the light-adapted retinas. Retinas were processed for standard light and electron microscopy after cardiac perf usion of the animal, with fixative containing glutaraldehyde and paraformaldehyde, and embedment in Epon 812 resin. Retinas for immunoelectron microscopy were fixed either by perfusion or immersion and embedded in L. R. White resin.

Antibodies and immunolabeling. Two different myosin VIIa antibodies were used. One was generated against a recombinant protein, including residues 941-1071 of mouse myosin VIIa. This tail domain antibody is the same as that referred to as polyclonal antibody (pAb) 2.2 by Liu et al. (1997a). This antibody was used for the electron immunomicroscopy. A newer antibody was produced by Affinity Bioreagents Inc. (catalog \#PA1-936) against a peptide corresponding to amino acids 16-31 of mouse, human, and porcine myosin VIIa. This N-terminal antibody was used in Western blot analysis of testis from Myo $7 a^{4494 S B}$ and Myo7a $a^{4626 S B}$ mice to test for the presence of a truncated myosin VIIa product. These alleles are both stop mutations: in $M y o 7 a^{4494 S B}$ the stop occurs after the first 245 amino acids of myosin VIIa plus five additional residues (theoretical molecular mass of $28 \mathrm{kDa}$ ), and in $M y o 7 a^{4626 S B}$ after the first 719 amino acids of myosin VIIa (theoretical molecular mass of $82 \mathrm{kDa}$ ) (Mburu et al., 1997). Five different opsin antibodies, which have been characterized previously, were used: two polyclonal antibodies, pAbs 01 and 99, generated in our lab against bovine opsin (Newton and Williams, 1993; Boesze-Battaglia et al., 1997); monoclonal antibodies (mAbs) 1D4 and 4D2, which recognize $\mathrm{C}$-terminal and $\mathrm{N}$-terminal epitopes, respectively (Molday, 1989); and mAb B6-30, which recognizes an N-terminal epitope (Adamus et al., 1988). The sections shown in Figures 2 and 3 were labeled with $\mathrm{pAb} 01$. The peripherin/rds antibody used is polyclonal against the C-terminal two-thirds of the mouse protein (Kedzierski et al., 1997). All electron immunomicroscopy was performed using secondary antibodies conjugated to $10 \mathrm{~nm}$ gold particles, as described (Liu et al., 1997a). Western blots of proteins from testes and neural retinas were performed as described (Liu et al., 1997a). 

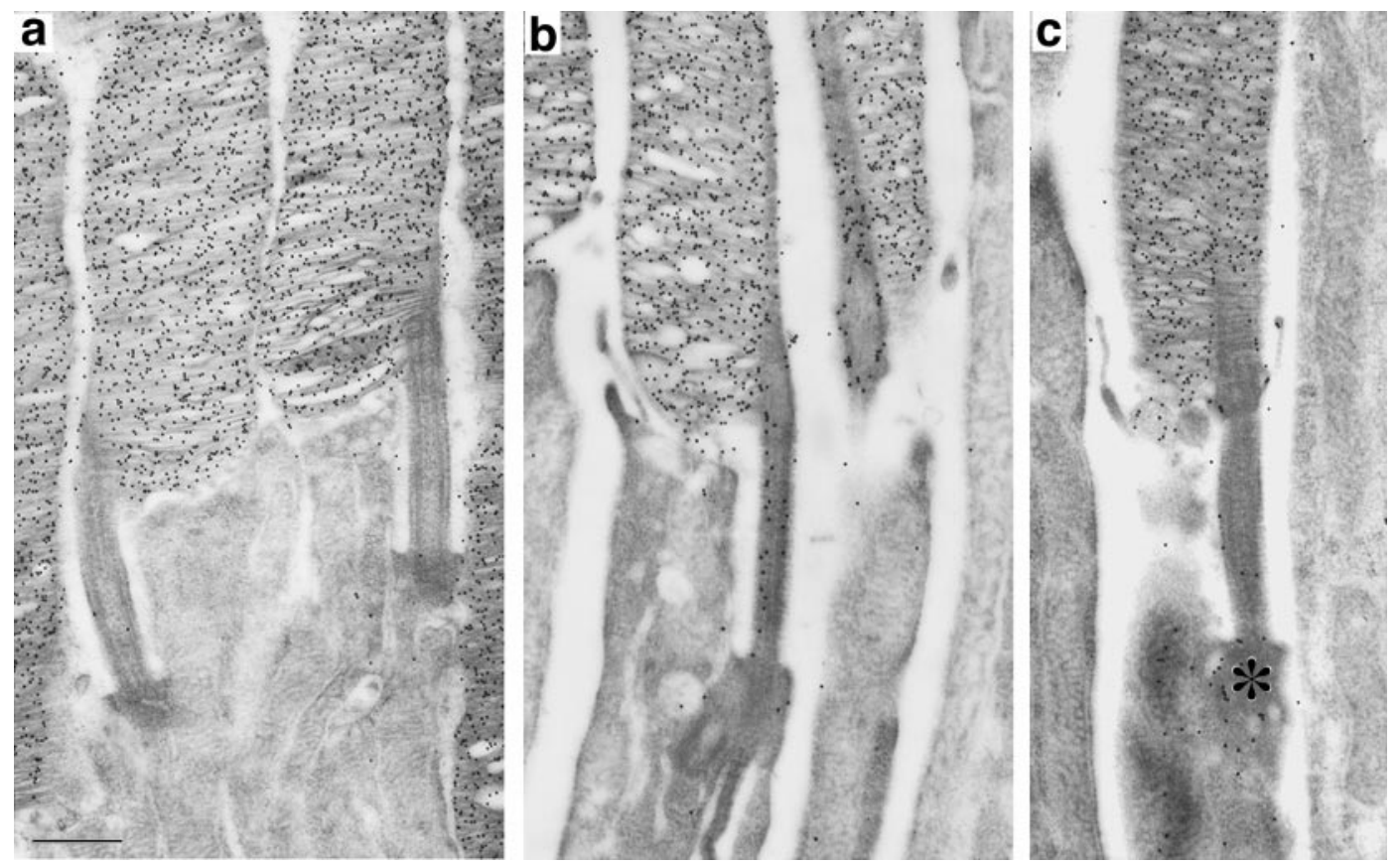

Figure 3. Immunogold localization of opsin in $M y o 7 a^{4626 S B}$ photoreceptor cells. $a$, Electron micrograph of a photoreceptor cell from a control littermate. Scale bar, $0.5 \mu \mathrm{m} . b, c$, Electron micrographs of photoreceptor cells from a homozygous mutant Myo7a $a^{4626 S B}$ mouse. Same magnification as in $a$. In $b$, there is an abnormal accumulation of opsin in the connecting cilium, like that in Figure $2 b$. In $c$, there is less opsin label in the connecting cilium, but an abnormal accumulation of opsin around the base of the cilium $\left(^{*}\right)$ is evident. The mice were 1.5 -month-old littermates.

Quantification of cells, outer segment length, and immunolabel. Photoreceptor cell nuclei, which make up the outer nuclear layer of the retina, were counted in sections from the same blocks as those used for autoradiography (see below), plus blocks of the same retinal regions from an additional 4-month-old $M y o 7 a^{s h 1}$ mutant/control pair of mice. Two sections from the central superior retina were analyzed for each retina. Care was taken to make sure that the photoreceptors were aligned longitudinally in these sections. Nuclei in three separate $110 \mu \mathrm{m}$ lengths of each section were counted using a light microscope. Data were expressed as number of nuclei per $6 \mu \mathrm{m}$. Because the horizontal spacing of the nuclei is $\sim 6 \mu \mathrm{m}$, the data represent the thickness of the photoreceptor nuclear layer in terms of number of nuclei. Rod outer length was measured from these same sections, by measuring 15 adjacent rod outer segments per section.

Opsin immunoelectron microscopy was examined in retinas from a total of $15 \mathrm{Myo}^{\mathrm{sh}} \mathrm{a}^{\mathrm{sh}}$ mutant/control pairs of mice (controls consisted of heterozygotes and wild types), three Myo $7 a^{4494 S B}$ mutant/control pairs of mice, and five Myo7a $a^{4626 S B}$ mutant/control pairs of mice. The Myo7a ${ }^{\text {sh } 1}$ mice ranged from 1 to 8 months old. The Myo7a $a^{4494 S B}$ mice were 3-6.5 months old. The Myo $7 a^{4626 S B}$ mice were $1.5-6$ months old. For quantification of the opsin immunogold label in the connecting cilium and in the inner segment plasma membrane, we used four Myo $7 a^{s h 1}$ mutant and four $M y o 7 a^{\text {sh } 1}$ heterozygous 3-month-old littermates and three $M y o 7 a^{4626 S B}$ mutant (all albino) and three littermate controls (one albino, two chinchilla-pigmented) of 1.5 or 4 months old. Counts were obtained with pAb 01 antibody (data shown) and also with mAb 1D4 (which gave similar data). Gold particles were counted along a $1 \mu \mathrm{m}$ length of the cilium, from just distal of the distal pair of basal body toward the base of the outer segment (Figs. $1 a, 2 b$ ). The entire length up to the most basal disk is $\sim 1.2-1.3 \mu \mathrm{m}$, but we deliberately excluded this last $0.2-0.3 \mu \mathrm{m}$ in our quantification to provide clear separation between the region counted and the heavily labeled outer segment. Counts were made only from connecting cilia that were in complete longitudinal section; 9-18 cilia were counted from each animal. The sections used showed similar densities of opsin label over the outer segment disks $(\sim 500$ gold particles per one square micrometer). Background label density (that in the extracellular space between photoreceptor cells) was subtracted from the counts, which were then normalized to a standard of 500 gold particles per one square micrometer over the outer segment disks. Counts of gold particles on the inner segment plasma membrane were made along a 1 $\mu \mathrm{m}$ length of plasma membrane, extending proximally from the basal body region, but excluding the periciliary ridge domain (Fig. 1a). Particles within $40 \mathrm{~nm}$ of the membrane were counted. Data were normalized as for those concerning the connecting cilium. Retinas from four $M y o 7 a^{s h 1}$ mutants and four littermate controls (heterozygotes or wildtype) were labeled with anti-peripherin/rds.

All measurements were made from slides or photographs that were labeled in code, so that the two individuals making the measurements were blind to the genotype. All data are represented as mean \pm SEM. Where appropriate, a one-tailed, Student's $t$ test was applied to test the probability of no significant difference.

Opsin content. The amount of opsin in each retina was measured from frozen eyeballs or detached neural retinas. It was found that the eyeballs gave a more accurate indication, because a significant amount of opsin was apparently lost during dissection of the eye to obtain the neural retina. Samples were homogenized by gentle sonication and subjected to SDS-PAGE followed by transfer to Immobilon P. Opsin was immunodetected using pAb 01 and chemiluminescence. The amount of opsin was quantified with reference to a standard curve established with purified mouse rod outer segments. The opsin concentration of the rod outer segments was determined from its absorbance spectrum before and after bleaching. Samples were analyzed in triplicate from each retina. Measurements were made from a total of four $M y o 7 a^{s h 1}$ mutants, four albino Myo $7 a^{4494 S B}$ mutants, four pigmented (agouti) Myo $7 a^{4626 S B}$ mutants, and four albino $M y o 7 a^{4626 S B}$ mutants, with an equal number of appropriate controls (same age and pigmentation).

Autoradiography. Myo $7 a^{\text {shl }}$ mice from a single litter containing three mutants, two heterozygotes, and two wild-type mice of 3 months old were used. They were given intraperitoneal injections of $70 \mu \mathrm{Ci}\left[{ }^{3} \mathrm{H}\right]$ leucine $(140 \mathrm{Ci} / \mathrm{mmol})$ per gram body weight. They were kept on a $12 \mathrm{hr}$ light/dark (40-100 lux) cycle, beginning 1 week immediately before the injection. Seven days after the injection, their retinas were prepared for light microscope autoradiography. This experiment was performed at UCSD. In a separate experiment, performed in Nottingham by a different investigator (K.P.S.), Myo $7 a^{4494 S B}$ and $M y o 7 a^{4626 S B}$ mice were used. The Myo $7 a^{4494 S B}$ mice came from two litters, one 5 months old, the other 6 months old. Together they contained four controls and three homozygous mutants. Two of the mutants were pigmented (chinchilla) like the controls, and one was albino. The relative band migration of the albino (62\% of that in controls) was less than that of the pigmented mutants; the data given in the results section exclude the measurement from this albino. The $M y o 7 a^{4626 S B}$ mice came from a single 3-month-old litter, and 
contained three pigmented (chinchilla) controls and three albino homozygous mutants. Mice were injected with $\left[{ }^{3} \mathrm{H}\right]$ leucine and taken for autoradiography $7 \mathrm{~d}$ later in the same manner as were the $M y o 7 a^{\text {shl }}$ mice. They were kept on a $12 \mathrm{hr}$ light/dark (90-570 lux) cycle, beginning 1 week before the injection.

For light microscope autoradiography, eyes were dissected, fixed by immersion in buffered paraformaldehyde, and embedded in Epon 812. Semithin sections $(0.5 \mu \mathrm{m})$ were prepared $0.5-1.0 \mathrm{~mm}$ from the ora serrata from six different regions across the superior hemisphere of each retina. Sections were oriented so that the photoreceptors were aligned longitudinally. They were dipped in 50\% Kodak (Eastman Kodak, Rochester, NY) NBT-2 emulsion at $43^{\circ} \mathrm{C}$ and exposed for $3-10$ weeks at $4^{\circ} \mathrm{C}$. After development, they were photographed. The photographs were labeled in code. The leading edge of the band of radiolabel was identified on the photographs, and the distances from the bases of 10 adjacent rod outer segments to the leading edge were measured and averaged from each of three regions of each photograph (the two sides and the center); i.e., 180 rod outer segments were measured from each retina. Both the identification of the leading edge of the radiolabel and the ensuing measurements were made by two individuals who were blind to the genotype.

\section{RESULTS}

Three different alleles of shaker1 mice were studied: the original line of shaker1 mice, Myo $7 a^{\text {sh } 1}$, and two others, Myo $7 a^{4494 S B}$ and Myo7a $a^{4626 S B}$ (Lord and Gates, 1929; Gibson et al., 1995; Mburu et al., 1997). The Myo7a ${ }^{\text {sh } 1}$ mutation results in an Arg502Pro substitution, which is in a surface loop near the putative actinbinding site (Gibson et al., 1995). This mutation most likely interferes with the motor function of the mutant myosin VIIa. The presence of this mutation was confirmed in our colony by DNA sequencing (Liu et al., 1998a). The Myo7a $a^{4494 S B}$ and $M y o 7 a^{4626 S B}$ mutations are both stop mutations near the $5^{\prime}$ end (Mburu et al., 1997). Various point mutations in the motor domain of myosin VIIa, including a Pro503Leu substitution (which is next to that of $M y o 7 a^{s h 1}$ ), as well as stop mutations in the motor domain, have been linked to Usher syndrome $1 \mathrm{~B}$ (Weston et al., 1996).

Labeling of Western blots of retinal proteins with myosin VIIa antibodies demonstrated that expression of mutant protein in Myo $7 a^{\text {sh } 1}$ mutant retinas was similar to that of the wild-type protein in wild-type retinas (data not shown), consistent with an earlier study, in which a different tail domain antibody was used (Hasson et al., 1997). An N-terminal antibody provided the same result with $M y o 7 a^{\text {sh1 }}$ testis and revealed that testis from $M y o 7 a^{4494 S B}$ and Myo $7 a^{4626 S B}$ mice contain not only no full length myosin VIIa but also no significant amount of a truncated product (data not shown), providing evidence that these two alleles are both effectively null.

There was no significant difference in photoreceptor number between mutants and controls up to 6 months old, indicating a lack of cell death during this period. The number of photoreceptor cell nuclei per $6 \mu \mathrm{m}$ of retina was $10.7 \pm 0.5$ in $M y o 7 a^{\text {sh1 }}$ mutants and $11.2 \pm 0.1$ in littermate controls, $9.7 \pm 3.0$ in Myo $7 a^{4494 S B}$ mutants and $9.6 \pm 0.1$ in littermate controls, and $11.2 \pm 0.7$ in $M y o 7 a^{4626 S B}$ mutants and $10.1 \pm 0.1$ in littermate controls. By electron microscopy, there was no discernible difference in photoreceptor cell ultrastructure, including cilium organization (cf. J. Cable, S. D. M. Brown, and K. P. Steel, in preparation).

Results from electron immunomicroscopy of photoreceptor cells of wild-type littermates of $M y o 7 a^{\text {sh } 1}$ mice agreed with our previous study with C57BL/6 mice, and rats and humans (Liu et al., 1997a), showing that normal myosin VIIa is concentrated in the connecting cilium. Within the connecting cilium, it appeared to be restricted to the periphery, outside the ring of microtubules
(Fig. 1b). Examination of Myo7ash1 mutant mice showed that mutant myosin VIIa was localized to this same region in a similar concentration (Fig. 1c). If the $M y o 7 a^{s h 1}$ mutation blocks the motor function of myosin VIIa, this result would mean that the protein does not depend on its own motor capabilities for correct targeting to its site of function.

To explore whether myosin VIIa might be involved in transporting phototransduction proteins between the photoreceptor inner and outer segments, we first examined the distribution of opsin, which accounts for $90 \%$ of the outer segment membrane protein (Papermaster and Dreyer, 1974), in shaker1 photoreceptor cells. Retinas from the three alleles of shaker1 mice were immunogold-labeled with opsin antibodies. Five different antibodies against different regions of the protein were used (see Materials and Methods), and all gave a similar result. Photoreceptor connecting cilia in wild-type and heterozygous $M y o 7 a^{\text {sh1 }}$, $M y o 7 a^{4494 S B}$, and $M y o 7 a^{4626 S B}$ retinas were only weakly immunoreactive (Figs. 2a, 3a), like those in published illustrations of wild-type retinas (Nir et al., 1984; Besharse et al., 1985). In contrast, connecting cilia from homozygous mutant mice were labeled relatively heavily in both light- and dark-adapted samples (Figs. 2b, 3b). Quantitatively, we found $14.6 \pm 1.1$ particles per 1 $\mu \mathrm{m}$ length of cilium in $M y o 7 a^{s h 1}$ mutants and $4.7 \pm 0.8$ particles in heterozygous littermates after normalization of particle density (see Materials and Methods). Before cell death in many types of photoreceptor degeneration, opsin is evident in the inner segment plasma membrane (Nir et al., 1987; Li et al., 1995). However, counts of label over the inner segment plasma membrane of these same mouse photoreceptor cells showed that there was just as little label in the mutants as in the controls (mean of 0.4 particles per micrometer in each), indicating that the increased label in the connecting cilium was not associated with a general loss-of-polarity response. Photoreceptor connecting cilia with an abnormally large amount of opsin label were also observed in Myo $7 a^{4494 S B}$ and Myo7a $a^{4626 S B}$ mutant retinas (Fig. 3); mean of $15 \pm 2$ particles in Myo $7 a^{4626 S B}$ mutants compared with $5.7 \pm 0.8$ in littermate controls. However, in a number of the photoreceptor cells of these null mutants, an abnormal amount of opsin label was more evident around the base of the cilium, rather than in the connecting region of the cilium (Fig. $3 c$ ). In an area at the base of the cilium, defined by a $0.5 \mu \mathrm{m}$ circle centered on the distal pair of basal bodies, a mean of $11.7 \pm 1.1$ particles was obtained from counts of mutant Myo $7 a^{4626 S B}$ photoreceptors compared with $5.1 \pm 0.6$ particles in littermate controls. This accumulation of label at the base of the cilium was not observed in $M y o 7 a^{\text {sh1 }}$ mutants, so that, overall, the abnormal accumulation of opsin is more conspicuous in the null Myo7a mutants.

Despite this altered distribution of opsin in mutant photoreceptor cell cilia, most of the opsin in the cell is still within the disk membranes. Measurements of total opsin in mouse eyes by Western blot analysis showed no significant difference between sameaged mutants and controls for each of the three alleles; mutants and controls both contained $0.8 \mathrm{nmol}$ of opsin per eye at 2 months old. There was also no significant difference in rod outer segment length; e.g., for 3-month-old Myo7a $a^{\text {shl }}$ littermates we measured $19.5 \pm 0.4 \mu \mathrm{m}$ in mutants and $20.3 \pm 0.7 \mu \mathrm{m}$ in controls. Together, these two measurements indicate that opsin concentration in the disk membranes is similar between mutants and controls, a result that is consistent with the relative intensities of opsin immunogold labeling of the disk membranes on ultrathin sections (Figs. 2, 3). 


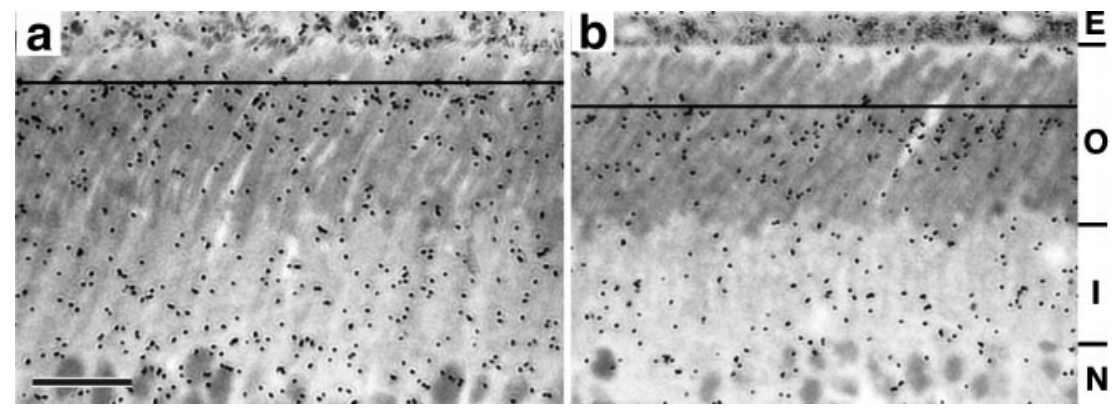

Figure 4. Light microscope autoradiographs of $M y o 7 a^{\text {sh } 1}$ retinas $7 \mathrm{~d}$ after the mouse received an injection of $\left[{ }^{3} \mathrm{H}\right]$ leucine. $a$, Retina from a heterozygous Myo $7 a^{\text {shl }}$ mouse. Scale bar, $10 \mu \mathrm{m}$. $b$, Retina from a homozygous mutant Myo $7 a^{\text {shl }}$ mouse. Same magnification as in $a$. The mice were 3-month-old littermates. The horizontal line represents the position of the leading edge of the band of radiolabel over the rod outer segments. Note that the region of outer segment above this band contains only background label because it contains disks that were formed as discrete units before the time of injection of radiolabel. $E$, Retinal pigment epithelium; $O$, rod outer segments; $I$, rod inner segments; $N$, photoreceptor nuclear layer.
To explore whether the distribution of other outer segment proteins might also be affected in shaker1 mice, we immunogoldlabeled retinal sections with antibodies against peripherin/rds, a membrane protein that is restricted to the disk rims (Molday et al., 1987; Arikawa et al., 1992; Kedzierski et al., 1997). Retinas from $M y o 7 a^{\text {sh } 1}$ and $M y o 7 a^{4626 S B}$ mutants and littermate controls were examined. In all mutant retinas, the distribution of peripherin/rds was the same as that in control retinas (data not shown). At the base of the outer segment, the distribution was like that described previously for wild-type retinas (Arikawa et al., 1992), with dense labeling of the disk rims and incisure and no significant label in the connecting cilium. This observation indicates that the abnormal accumulation of opsin is not the result of a general defect that perturbs the distribution of all outer segment proteins.

Last, we tested whether the rate of flow of opsin to the outer segment was perturbed in shaker1 mice, by using pulse-chase autoradiography to measure the rate of renewal of the opsincontaining disk membranes. Disks form as discrete structures so that those formed at the time of the pulse could be identified by a radiolabeled band (Young, 1967). The position of the leading edge of the radiolabeled band in each aligned retinal section was determined, and the distance from the base of each outer segment to this leading edge was measured to assess the amount of disk membrane made after the pulse. Because of some free $\left[{ }^{3} \mathrm{H}\right]$ leucine still present in the animals during the "chase" period, there was significant label in the photoreceptor cells below the band of radiolabel (as well as in other retinal cells). However, there was only background label above the band (i.e., in disks made before the pulse of radiolabel), which facilitated locating the position of its leading edge (Fig. 4). Band migration in Myo $7 a^{\text {sh } 1}$, Myo $7 a^{4494 S B}$, and Myo $7 a^{4626 S B}$ mutants was $86 \pm 3 \%, 87 \pm 2 \%$, and $70 \pm 5 \%$, respectively, of that in respective controls ( $p<0.01$, for each allele). Although $M y o 7 a^{\text {sh1 }}$ and Myo $7 a^{4494 S B}$ mutants had the same pigmentation as their controls, the $M y O 7 a^{4626 S B}$ mutants were albino, in contrast to their pigmented controls. This lack of pigmentation appeared to result in an exaggerated decrease in renewal rate; relative band migration in one $M y o 7 a^{4494 S B}$ albino mutant that was also included in the experiment (but not used for the data given above) was $62 \%$ of that in the pigmented controls. Therefore, although the magnitude of the effect was small, the disk renewal rate was consistently slower in the mutants of each of the three mutant alleles examined.

\section{DISCUSSION}

The results lead to the following conclusions about the function of myosin VIIa and the effects of mutant myosin VIIa in photoreceptor cells. First, myosin VIIa functions in the photoreceptor connecting cilium. Its immunolocalization in the cilium implies this, although the mutant phenotype associated with the cilium of shaker1 mice is stronger evidence of function in this structure. This phenotype is the first indication of a role for any myosin in a cilium. Because a cilium cytoskeleton is dominated by microtubules rather than actin filaments, it is surprising that a myosin would function in such a structure, although some actin filaments have been detected in the photoreceptor cilium (Vaughan and Fisher, 1987; Arikawa and Williams, 1989; Chaitin and Burnside, 1989).

Second, the abnormal increase in opsin in the connecting cilium of shaker1 mice provides the first clear illustration of opsin in this domain, and therefore, the first direct evidence that opsin may travel via the cilium en route from its site of synthesis in the inner segment to the outer segment. The inability to detect significant opsin in the connecting cilia of wild-type photoreceptors has led to the suggestion of opsin delivery to the outer segment by an extracellular route (Besharse and Horst, 1990; Besharse and Wetzel, 1995). However, if myosin VIIa carries opsin through the connecting cilium (see below), and it moves at a velocity similar to that measured in vitro for other myosins, such as myosin V (Cheney et al., 1993; Wolenski et al., 1995), opsin could be transported at about $500 \mathrm{~nm} / \mathrm{sec}$. Each mouse photoreceptor renews $\sim 87$ disks per day (Young, 1967; Besharse and Hollyfield, 1979), or, given an opsin concentration in the disk membrane of 20,000 opsins $/ \mu \mathrm{m}^{2}$ (Corless et al., 1976), it renews an average of $72 \mathrm{opsins} / \mathrm{sec}$. The area of a $1 \mu \mathrm{m}$ length of ciliary plasma membrane is $\sim 1 \mu \mathrm{m}^{2}$. At $500 \mathrm{~nm} / \mathrm{sec}$, opsin molecules would take $2 \mathrm{sec}$ to travel this $1 \mu \mathrm{m}$ length, so that, although the opsin renewal rate is high, the opsin concentration in the ciliary plasma membrane need only be $144 / \mu \mathrm{m}^{2}$ to support it. That is less than $1 / 100$ th of that in the disk membranes, making intense immunolabeling of opsin in the connecting cilium of a wild-type photoreceptor cell improbable.

The third conclusion is that myosin VIIa participates in the transport of opsin through the connecting cilium. The increase in opsin immunolocalized within and just proximal to the connecting cilium of shaker1 photoreceptors could arise from an increase in the amount of opsin traveling at the normal velocity to the outer segment, a normal amount of opsin traveling at a reduced velocity, or a reduced amount of opsin traveling at a very reduced 
velocity. The radiotracer experiments indicate that the renewal rate of disk membrane protein is slightly reduced in shaker1, so that the first alternative, which would be consistent only with an increase in the rate of protein renewal, appears unlikely. Arguably, the immunolocalization result could arise solely from back flow of some opsin from the outer segment into the connecting cilium. However, this would have the same effect on average opsin velocity (i.e., rate of net flow) to the outer segment as a reduced rate of transport through the cilium without back flow. Therefore, in shaker1, there is a small reduction in the rate of delivery of protein to the outer segments, and the more congested opsin must be traveling at a reduced average distal velocity through the connecting cilium. This suggests that transport through the cilium is not normally rate-limiting for disk membrane renewal in wildtype photoreceptors. Because myosin VIIa appears from its primary sequence to be a motor protein, it may be involved directly in the transport of opsin through the connecting cilium. Alternatively, it could have a more general role in the organization of the cilium, and thus affect opsin flow indirectly. However, the ultrastructure of the shaker1 photoreceptor cilium appears normal (present study; Cable, Brown, and Steel, in preparation), and myosin VIIa is not expressed in photoreceptor cells until 4-5 d after birth, which coincides with the onset of opsin expression and is after the cilium has been formed (X. Liu and D. S. Williams, in preparation).

That opsin can still get through the connecting cilium in the absence of normal myosin VIIa (i.e., there is not complete blockage) is consistent with other observations. First, shaker1 mice develop functional outer segments, and type 1B and atypical Usher syndrome patients have been reported to undergo progressive retinitis pigmentosa as opposed to congenital blindness (Fishman et al., 1983; Liu et al., 1997b, 1998b; Cuevas et al., 1998). Second, in vitro experiments with frog retinas show that short-term delivery of outer segment protein is largely unaffected in photoreceptors whose actin filaments (Williams et al., 1988) or microtubules (Vaughan et al., 1989) have been disassembled; although disassembly of both does inhibit delivery (Liu and Williams, in preparation). Perhaps there is some redundancy among molecular motors in transporting proteins to the outer segment. Known candidates that might be important in compensating for lack of myosin VIIa photoreceptor function include members of the kinesin superfamily (Beech et al., 1996; Muresan et al., 1997) and conventional myosin (myosin II) (Chaitin and Coelho, 1992; Williams et al., 1992), which have also been detected in the photoreceptor cilium.

Finally, the abnormal distribution of opsin is the first photoreceptor phenotype as a result of mutant myosin VIIa to be identified, and thus has implications for understanding the cellular basis of photoreceptor degeneration in type 1B and atypical Usher syndrome. Like others previously (Hasson et al., 1997), we did not observe obvious photoreceptor degeneration in shaker1 retinas. The reason why retinal degeneration resulting from mutant myosin VIIa has been observed only in humans is not clear. Possibilities include differences in the specific mutations between human and mouse (none of the reported Usher syndrome mutations are identical to those found in shaker1 mice) $)^{a}$, differences in genetic backgrounds, and/or differences between the species in the extent of redundancy in molecular motor function in the connecting cilium. Moreover, it is noteworthy that the rate of retinal degeneration typically varies greatly between man and mouse with the same genetic defect. In most examples studied so far, degeneration occurs more quickly in the mouse retina. For example, the rd mouse (which has a mutant $\beta$-phosphodiesterase gene) (Bowes et al., 1990) and some mouse opsin mutants incur photoreceptor degeneration before the photoreceptors are even fully developed (Carter-Dawson et al., 1978; Olsson et al., 1992). In other mutations, degeneration may occur more quickly in the human retina. In Usher 1 patients, including Usher $1 \mathrm{~B}$ patients, retinitis pigmentosa is first detected typically at $\sim 10$ years of age (Fishman et al., 1983; Liu et al., 1997b; Cuevas et al., 1998). If the deleterious effects of mutant myosin VIIa develop only slowly in a mouse retina, photoreceptor cell death may never become evident within a mouse's life span of 1-2 years. In any case, the lack of photoreceptor degeneration in shaker1 retinas enables us to determine that the observed cellular defects are not secondary to processes of cell death, and are instead the result of mutant myosin VIIa.

In the RPE, mutant myosin VIIa results in misplacement of the melanosomes (Liu et al., 1998a). However, as argued by Liu et al. (1998a), it is difficult to see how this defect in pigment distribution could in itself lead to photoreceptor degeneration, although it might exacerbate any light dependence of degeneration as a result of reduced light screening. The present study demonstrates an alternative cellular defect, one that resides in the photoreceptors themselves, and which perhaps is primarily responsible for the progressive degeneration found in type $1 \mathrm{~B}$ and atypical Usher syndrome. The ultrastructure of photoreceptors from donors with type 1B or atypical Usher syndrome have not been described. Interestingly, however, abnormally organized photoreceptor cilia have been observed in postmortem retinas from Usher syndrome type 2 patients (Barrong et al., 1992; Berson and Adamian, 1992; Hunter et al., 1986). The present observations suggest that the ciliary defect resulting from mutant or absent myosin V IIa affects opsin flow to the outer segment. Although the rate of outer segment protein renewal was found to be only slightly affected by this defect, this small effect could be deleterious over a prolonged period (i.e., years), or it could be larger under conditions of stress, or larger in humans compared with mice.

\footnotetext{
${ }^{a}$ Numerous mutations resulting in a stop within the motor domain have also been reported in Usher 1 patients. These may also be effective null mutations, but, in all cases except two, patients are not homozygous null (Weil et al., 1995; Weston et al., 1996; Adato et al., 1997; Levy et al., 1997; Liu et al., 1997b). The only possible exceptions have been found in (1) two siblings of an isolated family who appeared to be homozygous for a single base substitution, resulting in a Y333stop mutation (Weston et al., 1996); and (2) three siblings of an isolated family who appeared to be homozygous for a single base substitution, resulting in a C638stop mutation (Cuevas et al., 1998). In both these families, homozygosity was determined by the absence of the wild-type base from a PCR reaction, and it has not been determined whether these mutations are effectively null.
}

\section{REFERENCES}

Adamus G, Arendt A, Zam ZS, McDowell JH, Hargrave PA (1988) Use of peptides to select for anti-rhodopsin antibodies with desired amino acid sequence specificities. Peptide Res 1:42-47.

Adato A, Weil D, Kalinski H, Pel-Or Y, Ayadi H, Petit C, Korostishevsky M, BonneTamir B (1997) Mutation profile of all 49 exons of the human myosin VIIA gene, and haplotype analysis, in Usher 1B families from diverse origins. Am J Hum Genet 61:813-821.

Arikawa K, Williams DS (1989) Organization of actin filaments and immunocolocalization of $\alpha$-actinin in the connecting cilium of rat photoreceptors. J Comp Neurol 288:640-646. 
Arikawa K, Molday LL, Molday RS, Williams DS (1992) Localization of peripherin/rds in the disk membranes of cone and rod photoreceptors: relationship to disk membrane morphogenesis and retinal degeneration. J Cell Biol 116:659-667.

Barrong SD, Chaitin M, Fliesler S, Possin D, Jacobson S, Milam A (1992) Ultrastructure of connecting cilia in different forms of retinitis pigmentosa. Arch Ophthalmol 110:706-710.

Beech PL, Pagh Roehl K, Noda Y, Hirokawa N, Burnside B, Rosenbaum JL (1996) Localization of kinesin superfamily proteins to the connecting cilium of fish photoreceptors. J Cell Sci 109:889-897.

Berson EL, Adamian M (1992) Ultrastructural findings in an autopsy eye from a patient with Usher's syndrome type II. Am J Ophthalmol 114:748-757.

Besharse JC, Hollyfield JG (1979) Turnover of mouse photoreceptor outer segments in constant light and darkness. Invest Ophthalmol Vis Sci 18:1019-1024.

Besharse JC, Horst CJ (1990) The photoreceptor connecting cilium: a model for the transition zone. In: The photoreceptor connecting cilium: a model for the transition zone (Bloodgood RA, ed), pp 409-431. New York: Plenum.

Besharse JC, Wetzel MG (1995) Immunocytochemical localization of opsin in rod photoreceptors during periods of rapid disc assembly. J Neurocytol 24:371-388.

Besharse JC, Forestner DM, Defoe DM (1985) Membrane assembly in retinal photoreceptors. III. Distinct membrane domains of the connecting cilium of developing rods. J Neurosci 5:1035-1048.

Boesze-Battaglia K, Kong F, Lamba OP, Stefano FP, Williams DS (1997) Purification and light-dependent phosphorylation of a candidate fusion protein, the photoreceptor cell peripherin/rds. Biochemistry 36:6835-6846.

Bowes C, Li T, Danciger M, Baxter LC, Applebury ML, Farber DB (1990) Retinal degeneration in the rd mouse is caused by a defect in the $\beta$ subunit of rod cGMP-phosphodiesterase. Nature 347:677-680.

Carter-Dawson LD, LaVail MM, Sidman RL (1978) Differential effect of the rd mutation on rods and cones in the mouse retina. Invest Ophthalmol Vis Sci 17:489-498.

Chaitin MH, Burnside B (1989) Actin filament polarity at the site of rod outer segment disk morphogenesis. Invest Ophthalmol Vis Sci 30:2461-2469.

Chaitin MH, Coelho N (1992) Immunogold localization of myosin in the photoreceptor cilium. Invest Ophthalmol Vis Sci 33:3103-3108.

Chen ZY, Hasson T, Kelley PM, Schwender BJ, Schwartz MF, Ramakrishnan M, Kimberling WJ, Mooseker MS, Corey DP (1996) Molecular cloning and domain structure of human myosin-VIIa, the gene product defective in Usher syndrome 1B. Genomics 36:440-448.

Cheney RE, O'Shea MK, Heuser JE, Coelho MV, Wolenski JS, Espreafico EM, Forscher P, Larson RE, Mooseker MS (1993) Brain myosin- $\mathrm{V}$ is a two-headed unconventional myosin with motor activity. Cell 75:13-23.

Corless JM, Cobbs WH, Costello MJ, Robertson JD (1976) On the asymmetry of frog retinal rod outer segment disk membranes. Exp Eye Res 23:295-324.

Cuevas JM, Espinos C, Millan JM, Sanchez F, Trujillo MJ, GarciaSandoval B, Ayuso C, Najera C, Beneyto M (1998) Detection of a novel Cys628STOP mutation of the myosin VIIA gene in Usher syndrome type Ib. Mol Cell Probes 12:417-420.

Curcio CA, Sloan KR, Kalina RE, Hendrickson AE (1990) Human photoreceptor topography. J Comp Neurol 292:497-523.

El-Amraoui A, Sahly I, Picaud S, Sahel J, Abitbol M, Petit C (1996) Human Usher 1B/mouse shaker-1: the retinal phenotype discrepancy explained by the presence/absence of myosin VIIA in the photoreceptor cells. Hum Mol Genet 5:1171-1178.

Fishman GA, Kumar A, Joseph ME, Torok N, Anderson RJ (1983) Usher's syndrome: ophthalmic and neuro-otologic findings suggesting genetic heterogeneity. Arch Ophthalmol 101:1367-1374.

Gibson F, Walsh J, Mburu P, Varela A, Brown KA, Antonio M, Beisel KW, Steel KP, Brown SDM (1995) A type VII myosin encoded by mouse deafness gene shaker-1. Nature 374:62-64.

Guerin CJ, Lewis GP, Fisher SK, Anderson DH (1993) Recovery of photoreceptor outer segment length and analysis of membrane assembly rates in regenerating primate photoreceptor outer segment. Invest Ophthalmol Vis Sci 34:175-183.
Hasson T, Heintzelman MB, Santos-Sacchi J, Corey DP, Mooseker MS (1995) Expression in cochlea and retina of myosin VIIa, the gene product defective in Usher syndrome type 1B. Proc Natl Acad Sci USA 92:9815-9819.

Hasson T, Walsh J, Cable J, Mooseker MS, Brown SDM, Steel KP (1997) Effects of shaker-1 mutations on myosin-VIIa protein and mRNA expression. Cell Motil Cytoskeleton 37:127-138.

Hunter DG, Fishman GA, Mehta RS, Kretzer FL (1986) Abnormal sperm and photoreceptor axonemes in Usher's Syndrome. Arch Ophthalmol 104:385-389.

Kedzierski W, Lloyd M, Brich DG, Bok D, Travis GH (1997) Generation and analysis of transgenic mice expressing P216L-substituted rds/ peripherin in rod photoreceptors. Invest Ophthalmol Vis Sci 38:498-509.

Levy G, Levi Acobas F, Blanchard S, Gerber S, Larget Piet D, Chenal V, Liu XZ, Newton V, Steel KP, Brown SD, Munnich A, Kaplan J, Petit C, Weil D (1997) Myosin VIIA gene: heterogeneity of the mutations responsible for Usher syndrome type IB. Hum Mol Genet 6:111-116.

Li ZY, Kljavin IJ, Milam AH (1995) Rod photoreceptor neurite sprouting in retinitis pigmentosa. J Neurosci 15:5429-5438.

Liu X, Vansant G, Udovichenko IP, Wolfrum U, Williams DS (1997a) Myosin VIIa, the product of the Usher 1B syndrome gene, is concentrated in the connecting cilia of photoreceptor cells. Cell Motil Cytoskeleton 37:240-252.

Liu X-Z, Newton VE, Steel KP, Brown SDM (1997b) Identification of a new mutation of the myosin VII head region in Usher syndrome type 1. Hum Mutat 10:168-170.

Liu X, Ondek B, Williams DS (1998a) Mutant myosin VIIa causes defective melanosome distribution in the RPE of shaker-1 mice. Nat Genet 19:117-118.

Liu XZ, Hope C, Walsh J, Newton V, Mei KX, Liang C, Xu LR, Zhou JM, Trump D, Steel KP, Bundey S, Brown SDM (1998b) Mutations in the myosin VIIA gene cause a wide phenotypic spectrum including atypical Usher syndrome. Am J Hum Genet 63:909-912.

Lord EM, Gates WH (1929) Shaker, a new mutation of the house mouse (Mus musculus). Am Nat 63:435-442.

Mburu P, Liu XZ, Walsh J, Saw D, Jamie M, Cope TV, Gibson F, Kendrick-Jones J, Steel KP, Brown SDM (1997) Mutation analysis of the mouse myosin VIIA deafness gene. Genes Funct 1:191-203.

Molday RS (1989) Monoclonal antibodies to rhodopsin and other proteins of rod outer segments. Prog Retin Eye Res 8:173-209.

Molday RS, Hicks D, Molday LL (1987) Peripherin. A rim-specific membrane protein of rod outer segments. Invest Ophthalmol Vis Sci 28:50-61.

Muresan V, Bendala-Tufanisco E, Hollander BA, Besharse JC (1997) Evidence for kinesin-related proteins associated with the axoneme of retinal photoreceptors. Exp Eye Res 64:895-903.

Newton AC, Williams DS (1993) Rhodopsin Is the major in situ substrate of protein kinase $\mathrm{C}$ in rod outer segments of photoreceptors. J Biol Chem 268:18181-18186.

Nir I, Cohen D, Papermaster DS (1984) Immunocytochemical localization of opsin in the cell membrane of developing rat retinal photoreceptors. J Cell Biol 98:1788-1795.

Nir I, Sagie G, Papermaster DS (1987) Opsin accumulation in photoreceptor inner segment plasma membranes of dystrophic RCS rats. Invest Ophthalmol Vis Sci 28:62-69.

Olsson JE, Gordon JW, Pawlyk BS, Roof D, Hayes A, Molday RS, Mukai S, Cowley GS, Berson EL, Dryja TP (1992) Transgenic mice with a rhodopsin mutation (Pro23His): a mouse model of autosomal dominant retinitis pigmentosa. Neuron 9:815-830.

Papermaster DS, Dreyer WJ (1974) Rhodopsin content in the outer segment membranes of bovine and frog retinal rods. Biochemistry 13:2438-2444.

Papermaster DS, Schneider BG, Besharse JC (1985) Vesicular transport of newly synthesized opsin from the Golgi apparatus toward the rod outer segment. Invest Ophthalmol Vis Sci 26:1386-1404.

Vaughan DK, Fisher SK (1987) The distribution of f-actin in cells isolated from vertebrate retinas. Exp Eye Res 44:393-406.

Vaughan DK, Fisher SK, Bernstein SA, Hale IL, Linberg KA, Matsumoto B (1989) Evidence that microtubules do not mediate opsin vesicle transport in photoreceptors. J Cell Biol 109:3053-3062.

Weil D, Blanchard S, Kaplan J, Guilford P, Gibson F, Walsh J, Mburu P, Varela A, Levilliers J, Weston MD, Kelley PM, Kimberling WJ, Wagenaar M, Levi-Acobas F, Larget-Piet D, Munnich A, Steel KP, Brown 
SDM, Petit C (1995) Defective myosin VIIA gene responsible for Usher syndrome type 1B. Nature 374:60-61.

Weil D, Levy G, Sahly I, Levi-Acobas F, Blanchard S, El-Amraoui A, Crozet F, Philippe H, Abitbol M, Petit C (1996) Human myosin VIIA responsible for the Usher 1B syndrome: a predicted membraneassociated motor protein expressed in developing sensory epithelia. Proc Natl Acad Sci USA 93:3232-3237.

Weston MD, Kelley PM, Overbeck LD, Wagenaar M, Orten DJ, Hasson T, Chen ZY, Corey D, Mooseker M, Sumegi J, Cremers C, Moller C, Jacobson SG, Gorin MB, Kimberling WJ (1996) Myosin VIIa mutation screening in 189 Usher syndrome type 1 patients. Am J Hum Genet 59:1074-1083.

Williams DS, Linberg KA, Vaughan DK, Fariss RN, Fisher SK (1988)
Disruption of microfilament organization and deregulation of disk membrane morphogenesis by cytochalasin $\mathrm{D}$ in rod and cone photoreceptors. J Comp Neurol 272:161-176.

Williams DS, Hallett MA, Arikawa K (1992) Association of myosin with the connecting cilium of rod photoreceptors. J Cell Sci 103:183-190.

Wolenski JS, Cheney RE, Mooseker MS, Forscher P (1995) In vitro motility of immunoadsorbed brain myosin-V using a Limulus acrosomal process and optical tweezer-based assay. J Cell Sci 108:1489-1496.

Wolfrum U, Liu X, Schmitt A, Udovichenko IP, Williams DS (1998) Myosin VIIa as a common component of cilia and microvilli. Cell Motil Cytoskeleton 40:261-271.

Young RW (1967) The renewal of photoreceptor cell outer segments. J Cell Biol 33:61-72. 